\title{
Sustainable Development and Corporate Social Responsibility: The Case of Corinth Pipeworks S. A.
}

\author{
Kartalis Nikolaos ${ }^{1} \&$ Tsimpri Eugenia ${ }^{2}$ \\ ${ }^{1}$ School of Economics, University of Western Macedonia, Kozani, Greece \\ ${ }^{2}$ School of Business Administration, Hellenic Open University, Patra, Greece \\ Correspondence: Kartalis Nikolaos, School of Economics, University of Western Macedonia, Kozani, Greece. \\ E-mail: kartalisdn@gmail.com
}

Received: March 28, 2020

doi:10.5539/jsd.v13n3p150
Accepted: April 21, $2020 \quad$ Online Published: May 31, 2020

URL: https://doi.org/10.5539/jsd.v13n3p150

\begin{abstract}
Investors around the world show steadily increasing support for environmental and social issues. Therefore, the majority of the companies are in favor of adopting sustainable and socially responsible actions. On one hand, Corporate Social Responsibility, according to which companies operate considering the common good of society and environment, assist in reducing environmental and social problems, but always focusing in respect of people, society and economy. On the other hand, there is the Sustainable Development, which follows the same parameters as CSR (Economy, Environment and People), with the difference that -in the light of economic growth- corporations look forward and plan their changes in order to secure their future (i.e. reducing waste, assuring supply chains, developing new markets, health and safety, etc.). In the first part of the article, both of the concepts above -namely SD and CSR-will be investigated with the aid of literature review, targeting in to not only comprehend their importance but also to recognize the changes that have occurred throughout the decades. Moreover, the article will be focused in current global standards such as GRI and ISO 26000. In the second part, through the presentation of Corinth Pipeworks S.A. case study, it will be compared how the above concepts (as well as GRI and ISO 26000) operate in a company's real time and will be examined, how those practices have evolved in a three years' time-period.
\end{abstract}

Keywords: corporate social responsibility, sustainable development, GRI, ISO 26000, case study

\section{Introduction}

The research topic of the present article is the CSR and SD notion and the investigation of its numerous facets. The complexity and the multidimensional extent of both notions (CSR \& SD) predicate the use of the case study method in order to conduct the present paper.

In this context this article will examine the CSR and SD activities of Corinth Pipeworks SA through a comparative analysis of their Sustainability Reports from 2015 to 2017. CP is a world-leading manufacturer of steel pipe and hollow sections and a main supplier of the energy and construction industries. The company has been founded in the late 60's and since then it aims at the continuous development not only of its products but also of its personnel and always in respect of the environment and society, holding a strong socially responsible profile.

The study is based on secondary data, and more specifically on documentary information. Following the extraction and process of the secondary information from CP's annual reports, quantitative, but mostly qualitative results, will be presented so as the impact of the above-mentioned global impacts in the real corporation environment to be understood, Referring to the above-mentioned data, they include both quantitative and qualitative information, with the latter accounting a significantly larger share. The case study of the present paper constitutes a single case study, which can be considered as a descriptive one, due to the extensive analysis of CSR and SD notion in its context.

In the previous paragraphs and chapters both, the historical and theoretical background of CSR and SD notions has been presented and analyzed revealing their multidimensional extent. The compliance with and acceptance of the notions incorporates processes concerning its integration into business policies, principles, strategies and organizational structure. However, despite the extent and depth of the above-mentioned theoretical and practical 
aspects of the notions, the present paper could have been considered inconclusive if a case study on Corinth Pipeworks SA Corporate Social Responsibility Report was not performed. For the reason above and for enhancing awareness of the notion the discussion will be herewith proceed by elaborating this type of research.

In this paper we focus if all the key issues related to Corinth Pipeworks and its subsidiaries, individual targets for Corporate Social Responsibility and Sustainable Development are set, which are evaluated on an annual basis for their effectiveness and are revised when necessary. We examine the policy, the results of the Corinth Pipeworks on Corporate Social Responsibility, as well as the implementation of the programs and the achievement of the objectives, are published on an annual basis in order to inform all the stakeholders. In addition we take the views of stakeholders under consideration in order to manage all the annual Management Review to all the above issues.

\section{Global Practices and Initiatives for CSR and SD}

At the third Meeting of the parties held in December 1997 in Kyoto, the members of the United Nations, who signed the United Nations Framework Convention on Climate Change (UNFCCC) in 1992, accepted the Kyoto Protocol.

It is a milestone for the policy on climate change (internationally and nationally) as:

a) It is the first substantial legal commitment to jointly reduce greenhouse gas emissions by $5.2 \%$ with a concentration reference of year 1990 for the first commitment period 2008-2012.

b) Its signature in 1997 by thirty-nine developed countries has launched a series of new policy tools.

These countries were: Australia, Austria, Belgium, Bulgaria, Canada, Croatia, Czech Republic, Denmark, Estonia, Finland, France, Germany, Greece, Hungary, Iceland, Lithuania, Luxembourg, Monaco, Netherlands (Netherlands), New Zealand, Norway, Poland, Portugal, Romania, Russian Federation, Slovakia, Slovenia, Spain, Sweden, Switzerland, United Kingdom of Great Britain and Northern Ireland and the United States of America (Kyoto Protocol, 1997).

Each of these countries has undertaken a binding target to reduce or contain the increase in national greenhouse gas emissions. However, it was not a binding agreement for developing countries, such as India and China (ranked in the top 10 greenhouse gas emissions countries, according to WRI, 2014), nor did it contain a separate article for states that would commit binding targets on a voluntary basis. Its implementation would require ratification by 55 members of the Summit, which would have to concentrate at least $55 \%$ of the $\mathrm{CO} 2$ emissions of the reference year 1990 (Kyoto Protocol, Article 24, 1997). It was eventually ratified and came into force eight years later, on 16 February 2005 (UNFCCC, 2016a).

In an attempt to bridge the differences between developed and developing countries and, at the same time, to carry out the commitments in a satisfactory way, the participating countries have agreed in introducing the following three new policy tools:

\section{i) Joint Implementation (JI) Mechanism}

These are international cooperation programs, funded and hosted by signatory countries (countries listed in Annex B of the Kyoto Protocol and included in Annex I of the United Nations Framework Convention on Climate Change, Articles 3 and 6 of the Kyoto Protocol). The programs aim to the emissions reduction from man-made sources or to the creation of greenhouse gas absorption/storage in any sector of the economy. They are related to investments in renewable energy sources, reforestation, carbon storage and improvement of energy efficiency of industrial facilities, etc. These programs lead to the production of credits or Emission Reduction Units (ERUs). Depending on the agreement on the distribution of ERUs, these are added entirely or in part to the amount of Assigned Amount Units (AAUs), which are attributable to the country's emissions making the investment, while being deducted from the corresponding amount of the country hosting such programs (Article 3, paragraph 11). The programs started to be implemented by 2000, but the ERUs have been in force since 2008 (UNFCCC, 2016b).

\section{ii) Clean Development Mechanism (CDM)}

It refers to programs of the same type as Joint Implementation (JI) programs and was designed for programs between countries listed in Annex B of the Protocol and countries not included in it. As specified in Article 12 of the Protocol, the main objectives are:

a) to encourage the substantial development of countries not included in Annex B of the Protocol through technology transfer and energy efficiency and 
b) to enable Annex B countries to meet their commitments according to the Kyoto Protocol in a cost-effective way through reduction programs in non-Annex B countries (mainly non-industrialized countries which have not undertaken to reduce their greenhouse gases emissions).

The reductions achieved in these programs are called Certified Emission Reductions (CERs). Noted that, the nuclear power programs are excluded from the CDM. The CDM has been in operation since 2006 and more than 1.650 programs have been registered, with an estimate of CERs of more than 2,9 billion tons of CO2eq for the first binding period of the Protocol, 2008-2012 (UNFCCC, 2016c).

\section{iii) Emissions trading}

The Protocol permits emissions trading for a country that, while committed to reducing its emissions by a certain percentage, ultimately achieves a larger emission reduction (Article 16) and then acquires the opportunity to sell the excess stake in another country. The same can happen in the case that a country achieves a smaller increase than the one for which it has bound. In the same context companies are included that achieve emissions reduction, thus gaining the right to sell their reductions on international and / or national markets within the framework of business opportunities created by the implementation of the Kyoto Protocol. The operation of the international Emissions Trading, with a year of implementation in 2008, is based on the trading systems already in place, such as the European Trading System, (in operation since 2005), Canada's (the Quebec trading system launched in 2012), Kazakhstan's (since 2013), China's (pilot systems started in 2013 and 2014), Japan's (two systems since 2010 and 2011), New Zealand's (since 2008), South Korea's (since 2015), Switzerland's (voluntarily since 2008 and fully operational since 2013) and the United States of America (two since 2009 and 2012) (European Commission, DG Clima, 2016).

Canada withdrew from the Kyoto Protocol on 15 December 2012, while the United States did not ratify it (UNFCCC, 2016). At the Doha Conference of the Parties in Qatar in December 2012, the Doha Amendment to the Kyoto Protocol was adopted, with which the second commitment period of the Protocol starts, from 2013 until 2020. For the second binding period, the US, Canada, Russia and Japan have not undertaken binding targets such as the European Union and Australia.

Today, the Framework Convention on Climate Change lists 197 members, while the Kyoto Protocol 192 (UNFCCC, 2016). At the Paris Conference of the Parties in France in December 2015, the Paris Agreement, which will succeed the Kyoto Protocol, was adopted.

The 21st Conference of Parties of the United Nations Framework Convention on Climate Change adopted the Paris Agreement on 12th of December 2015. This global agreement, which is the result of long-term negotiations and will succeed the Kyoto Protocol, provides the framework for international actions aimed at addressing and adapting to climate change after 2020. This year is also the upper end second commitment period of the Kyoto Protocol and the framework of the agreement is outlined in 29 articles (The Paris Agreement, 2015).

Its objective is to hold the global temperature increase below $2^{\circ} \mathrm{C}$ compared to the pre-industrial levels while supporting efforts to limit the increase to $1,5^{\circ} \mathrm{C}$ (Article 2 of the Agreement). It also aims at ensuring the peak concertation of global greenhouse gas emissions as soon as possible and balancing the emissions and removals in the second half of this century. The articles 2, 3, 4, 5 and 6 concern the reduction of climate change.

The International Organization for Standardization (ISO) decided in 2004 to develop an internationally accepted standard, appropriate for each organization, in plain language understandable to non-experts, which would provide guidelines for CSR. This model was introduced in 2010 and named as ISCO 26000, Guidelines for Social Responsibility. It aims to be the first step of assistance to all types of public and private organizations so as with its implementation the benefits of operating in a socially responsible way to be achieved.

The needs arising and benefits arising from the implementation of social responsibility, whose aim is to contribute to SD, are commonly accepted internationally by businesses and stakeholders.

The behavior of a business in relation to the society in which it operates and its impact on the environment is a crucial measure of its overall performance and its ability to function effectively. This is partly the reflection of the growing recognition of the need to ensure healthy ecosystems, social equity and good organizational management. Ultimately, all business actions depend on the health of global ecosystems and lie under the microscope of the stakeholders.

The ISO 26000 standard aims at assisting the organizations for the contribution to SD. It aims at encouraging businesses to move beyond compliance with the law, recognizing that compliance with the law is a fundamental duty of every business and a necessary element of their social responsibility. It also intends at promoting a common understanding in the field of social responsibility and complementing other tools and initiatives, not 
replacing them.

For the implementation of ISO 26000, it is recommended that the company takes into account the social, environmental, legal, cultural, political and organizational diversity as well as the different economic conditions and at the same time be consistent with international standards of conduct.

The template is not certifiable but it has advisory use. Any attempt of ISO 26000 certification would mean misinterpretation of its objectives, misuse of the international standard and lack of compliance with it. The ISO 26000 includes seven key social responsibility issues that are defined in the standard as follows:

1) Accountability,

2) Transparency.

3) Ethics.

4) Respect of interests

5) Respect of rights:.

6) Respect of laws

7) Respect of rules

The GRI supports businesses and governments globally to recognize and channel their impact on critical sustainability issues, such as climate change, governance, human rights and social well-being. This empowers real action to create social, environmental and economic benefits for every person. The GRI Sustainability Reporting Standards are developed with true multi-stakeholder contributions and are embedded in the public interest.

The GRI Sustainability Reporting Standards, i.e. GRI Standards, are the initial and most widely adopted global standards for sustainability reporting. Since the inception of GRI in the year of 1997, it has been transformed from a specialized practice to a broadly adopted practice by an increasing majority of organizations. In reality, almost nine out of ten of the world's largest-ranked 250 corporations are reporting on their sustainability performance.

The practice of disclosing sustainability information encourages accountability, assists in identifying and managing risks, and empowers organizations to seize new opportunities. Reporting according to the GRI Standards assists companies of all types, public and private, and size, large and small, in protecting the environment and improving the society, while simultaneously flourishing economically by improving governance and stakeholder relations, enhancing their reputation and building trust.

GRI promotes the use of sustainability reports as a way through which organizations can become more sustainable and contribute to SD.

\section{i. $\quad$ Benefits of reporting}

An effective sustainability reporting cycle, including a systematic procedure of data collection, communication, and responses, would benefit, both internally and externally, all the reporting organizations.

In order to meet its targets and deliver on its mission, GRI has identified four key areas for the upcoming period:

1) Creation of standards and guidance to enhance sustainable development

Leading the market by consistently disclosing on sustainability-related subjects, including the engagement with stakeholders on surfacing sustainability issues.

2) Harmonization of the sustainability landscape

Lay the GRI in the core of sustainability reporting frameworks and initiatives, and choose cooperation and partnership opportunities serving GRI's vision and mission.

3) Leading an efficient and effective sustainability reporting

Develop and enhance the quality of disclosures generated using the GRI Standards, reducing the reporting load and further exploring reporting processes which encourage decision-making.

4) Drive effective use of sustainability information towards improving performance

Cooperate with policy makers, stock exchanges, regulators and investors to drive transparency and enable effective reporting. 


\section{ii. $\quad$ GRI G4 Guidelines}

GRI Sustainability Reporting Guidelines are considered by many nowadays the most recognized internationally. They consist of disclosure categories, which organizations can gradually include in an annual report, thereby enhancing their transparency on sustainability issues. Depending on the international acceptance of GRI in our country, the vast majority of sustainability reports, which issued annually, are drawn up on the basis of these guidelines.

The latest version of the Guidelines, called G4, which is a transformation of the GRI-G3 and GRI-G3.1 versions, was published in May 2013 to provide strategic importance to sustainability reports, making them more meaningful, reliable and easy to use. The goal of the GRI organization is to make non-financial reports as necessary, useful and usable, as the financial data reports.

\subsection{Transforming our World: The Agenda 2030 for Sustainable Development}

The Sustainable Development Goals (SDGs) are the blueprint to accomplish a better and more sustainable future for the humankind. They address the global challenges we confront, including those associated with poverty, inequality, climate, environmental degradation, prosperity, peace and justice. The goals are interrelated and in order to leave anything untackled, it is imperative that each goal and target shall be met and achieved by 2030 .

In September 2015, as part of the $70^{\text {th }}$ United Nations General Assembly (UN), 193 Member States adopted a plan to build a better future for everyone. For the next 15 years, the Goals for the eradication of extreme poverty, combating inequality and injustice and the environmental protection of the planet (Sustainable Development Knowledge Platform) have been defined.

They therefore create implementation commitments for countries either developed or developing, taking into account the significant national variances at development level and at national policy and priority levels. Thus, the three dimensions of Sustainable Development -Social, Environmental and Economic- are integrated and the interconnection of the SDG-related policies and the enforced legislative frameworks that will assist in the alignment with the Goals (General Secretariat of the Government) are promoted.

At the heart of the "AGENDA 2030" (United Nations, Transforming Our World: The 2030 AGENDA for Sustainable Development, 2015) are the 17 Sustainable Development Goals (SDGs) and the 169 specific targets, that are related to them and refer to the most important challenges of our time. These challenges take on the full range of activities, such as economic, social, and environmental and the governance challenges as well (CSR Hellas). 


\section{SUSTAINABLE GM}
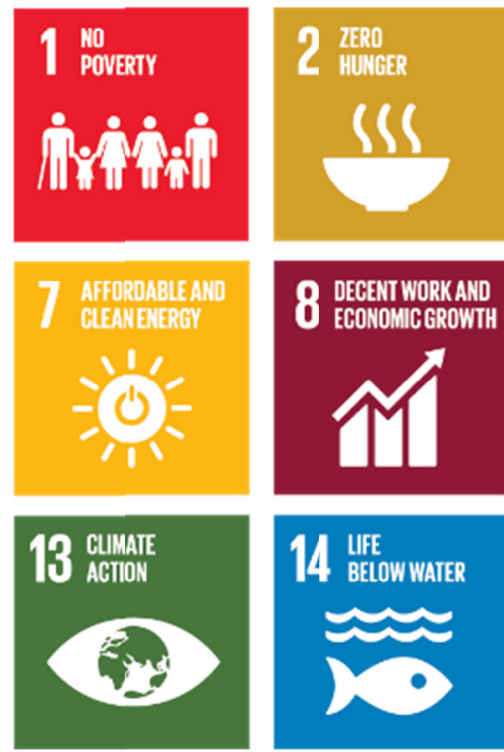
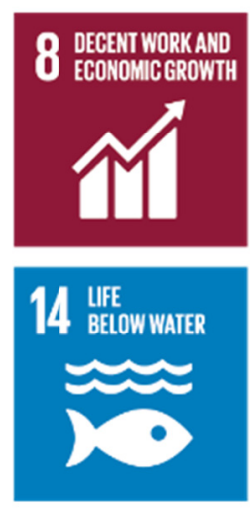
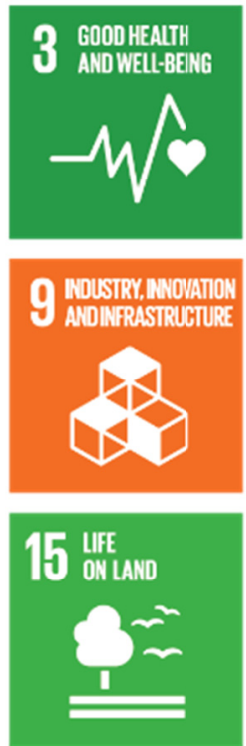
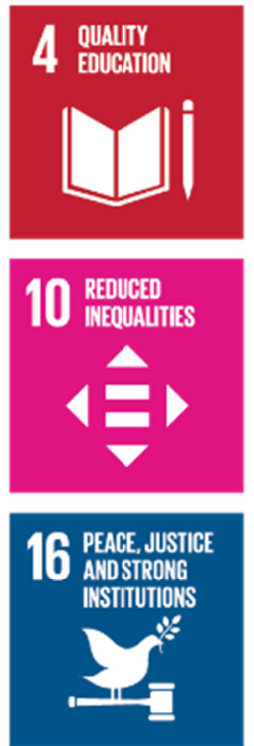
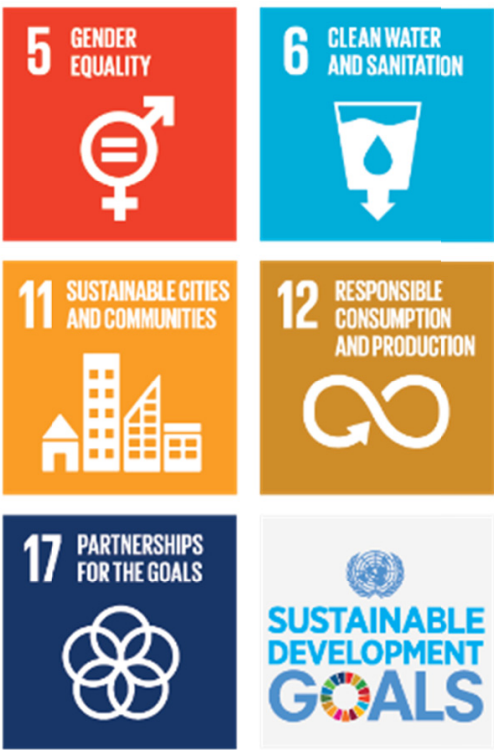

SUSTAINABLE DEVELOPMENT GALS

Figure 1. The sustainable development goals

The companies are also an integral link of the chain of the efforts to harmonize and implement the SDGs. Each company can have an important role in the achievement of SDGs, while the successful implementation of the SDGs sub-targets can enhance the creation of a favorable environment for business activity and the creation of new markets worldwide. Therefore, the SGDs are a very strong expectation for improving the world, trying to map out a path that has to be walked through collectively.

\section{Methodology}

According to Yin (2003), the case study method has been and still is, considered as a weak research method and the deriving studies have been consequently deprecated as having insufficient precision, objectivity or rigidity. However, scholars (Gerring, 2007) counter argue that this negative standpoint derives from the poor comprehension of the particular method. At this point, it is essential to stress out the importance of understanding the research philosophy and approach, as it delivers for the examined information and data to be successfully interpreted into answers of the researched topics.

The Case Study method is the most widely used method of scientific research and is applied in many sciences, such as sociology, psychology, economic and political sciences, and so on. This methodology, which is usually qualitative, is more preferable to other research strategies (experiment, file analysis, survey, historical review) when "how" and "why" questions have to be answered, when the researcher has little control over of events and when the focus of the study is on a modern phenomenon (Yin, 2003). In addition, the case study methodology is appropriate when the research sector is not commonly known and the researcher deals with a 'theory building' (Eisenhardt, 1989). Ghauri (2004) argues that the case study is a flexible research approach that is suitable for a range of different types of research questions. Several researchers have provided various definitions for the Case Study method.

According to Yin (2003), the case study is an empirical research that explores a contemporary phenomenon within a real context, especially when the boundaries between the phenomenon and the general context are not apparent and in which multiple sources of data and theoretical assumptions are used, guiding to the collection and analysis of data. Woodside and Wilson (2003) provided a broader definition than that of Yin (2003), i.e. the case study is a research focusing on description, understanding, predicting and / or controlling the subject (e.g. process, animal, individual, household, organism, group, industry, culture or nationality). Finally, according to Eisenhardt (1989), the case study is defined as a research strategy that focuses on understanding the dynamics 
presented in individual environments.

The research topic of the present paper is the CSR and SD notion and the investigation of its numerous facets. The complexity and the multidimensional extent of both notions (CSR \& SD) predicate the use of the case study method in order to conduct the present paper.

In this context this paper will examine the CSR and SD activities of Corinth Pipeworks SA through a comparative analysis of their Sustainability Reports from 2015 to 2017. CP is a world-leading manufacturer of steel pipe and hollow sections and a main supplier of the energy and construction industries. The company has been founded in the late 60's and since then it aims at the continuous development not only of its products but also of its personnel and always in respect of the environment and society, holding a strong socially responsible profile.

The study is based on secondary data, and more specifically on documentary information. Following the extraction and process of the secondary information from CP's annual reports, quantitative, but mostly qualitative results, will be presented so as the impact of the above-mentioned global impacts in the real corporation environment to be understood, Referring to the above-mentioned data, they include both quantitative and qualitative information, with the latter accounting a significantly larger share. The case study of the present paper constitutes a single case study, which can be considered as a descriptive one, due to the extensive analysis of CSR and SD notion in its context.

In the previous paragraphs and chapters both, the historical and theoretical background of CSR and SD notions has been presented and analyzed revealing their multidimensional extent. The compliance with and acceptance of the notions incorporates processes concerning its integration into business policies, principles, strategies and organizational structure. However, despite the extent and depth of the above-mentioned theoretical and practical aspects of the notions, the present paper could have been considered inconclusive if a case study on Corinth Pipeworks SA Corporate Social Responsibility Report was not performed. For the reason above and for enhancing awareness of the notion the discussion will be herewith proceed by elaborating this type of research.

The type of archival study to be used in this article includes research data, such as data collected from previous research by researchers related to the on sustainable development and social responsibility.

These files can be used in conjunction with other sources of information when conducting a case study. In this work, the files are so important that they are subject to extensive retrieval and quality analysis. In any case, a researcher must be careful to determine the terms under which it is produced and their accuracy. Sometimes the files can be very quantitative, but the numbers should not automatically be considered a sign of accuracy.

This section examined the commonly used sources of evidence for the application of a case study. The collection of all kinds of evidence must be developed and mastered independently to ensure that each source is used properly. Not all sources can be relevant to all case studies. However, the researcher should be aware of the procedures associated with the use of each source of evidence or have colleagues who have the required know-how and who can work as members of the case study team to maximize its reliability. These sources of evidence will, for the most part, be used in combination in the present study to draw as complete and safe a conclusion as possible regarding the effectiveness of the sustainable development and social responsibility of the Corinth Pipeworks S.A.

\section{Corinth Pipework's Social Responsibility and Sustainable Development and Strategy}

\subsection{The Organization}

Corinth Pipeworks, a company of the Viohalco Group, is one of the leading international steel pipes and hollow sections manufacturers in the energy and construction sectors.

Since 1969 until today, the company has gone through a rather successful course in the production and distribution of steel pipes. Throughout its business activity, it has implemented continuous improvements and changes in systems and operations making the company more effective and securing the Sustainable Development.

In 2016, Corinth Pipeworks Holding S.A. was merged by absorption by the Belgian company Cenergy Holdings S.A., which became a $100 \%$ shareholder of the Corinth Pipeworks Industry S.A. The headquarters of Corinth Pipeworks is in Greece, and it has subsidiary companies in the United States of America and Poland. Warsaw Tubular Trading's main object and business in Poland is its participation in companies of a similar business activity. In this context, the subsidiary Warsaw Tubular Trading holds $100 \%$ of the shares of CPW America Co. (USA), which markets Corinth Pipeworks products and has undertaken the servicing of its customers in North 
and South America. In Greece, Pipeworks holds 21,75\% of Dia.Vi.Pe.ThiV.. SA, which is responsible for the management of the institutionalized industrial area of Thisvi, within which the main production unit of the Company is located and operates.

\subsubsection{Vision, Mission and Values}

Corinth Pipeworks is constantly evolving, remaining faithful to its vision, mission and values. Corporate commitments, combined with the philosophy of pursuing the excellence it adopts, drives the conduct and the way it deals with customers, associates, suppliers and all its stakeholders.

\section{b. Vision}

To strengthen its leading position in the global steel pipe market, to be recognized by its customers as a first choice supplier, to provide significant opportunities for development to its personnel, to contribute to the development of the local communities and ensure maximum return for its shareholders.

c. Mission

- Creating added value for the shareholders.

- Supporting its customers by offering high quality products.

- Operating with health and safety in mind.

- Respecting the environment.

- Investing in the personal development of people.

- Developing long-term relationships with suppliers.

- Contributing to the development of local communities.

\section{d. Values}

- Integrity - Corporate Social Responsibility:

- Commitment.

- Focus on Results.

- Technological innovation and pioneering

- Team spirit

- Meritocracy

4.1.2 Corporate Governance for CSR and SD and International Standards

\subsubsection{Corporate Governance}

Corinth Pipeworks, in pursuit of maximizing value for the benefit of its shareholders, contributors to its development, as well as society in general, has developed its corporate governance framework, taking into account international practices and standards such as GRI-G4 and ISO 26000.

In particular, with a view to safeguarding the rights of the Company's shareholders, Corinth Pipeworks follows and complies with the applicable national law on Corporate Governance and has voluntarily adopted the Greek Corporate Governance Code, which has been recently published by the Hellenic Corporate Governance Council (HCGC), along with the deviations that are depicted in the Annual Financial Report.

The purpose of Corinth Pipeworks is to continuously evaluate and update its governance system in order to ensure that its entire range of activities and all transactions with its stakeholders is characterized by transparency, reliability and trust.

The Corinth Pipeworks shall ensure that its shareholders and potential investors, as well as any interested party, are provided with adequate, valid and timely information through its Organized Corporate Governance System, which includes:

- Administrative bodies with clear roles, responsibilities and obligations,

- Appropriate organizational structure and corporate processes,

- An effective internal control system;

- An organized communication system both with the external and its internal environment. 


\subsubsection{Sustainability Strategy}

Corinth Pipeworks recognizes the strategic importance of integrating the principles of Sustainable Development Policy into its entire organization and is systematically approaching the implementation of programs per axis.

Corporate Responsibility is an integral part of the decision-making process of strategy, management, research and development, production and other core sectors of the Corinth Pipeworks. The strategic integration of CSR into the Company also includes the social commitment of Corinth Pipeworks to local community in which it operates and develops. In addition, developing a stakeholder dialogue contributes to better map the impact of its activities separately on each stakeholder group. The systematic dialogue with all stakeholders helps the Company to handle effectively and respond properly to social and environmental issues, as well as to discover new challenges and new areas of activity or opportunities.

The strategic integration of CSR in Corinth Pipeworks is realized through planning, engagement with all stakeholders, performance appraisal and continuous improvement.

\subsubsection{International standards compliance table}

The adoption of Sustainable Development principles generates significant value for Corinth Pipeworks, particularly when it reflects the requirements of applicable initiatives and standards. Specifically, at Corinth Pipeworks:

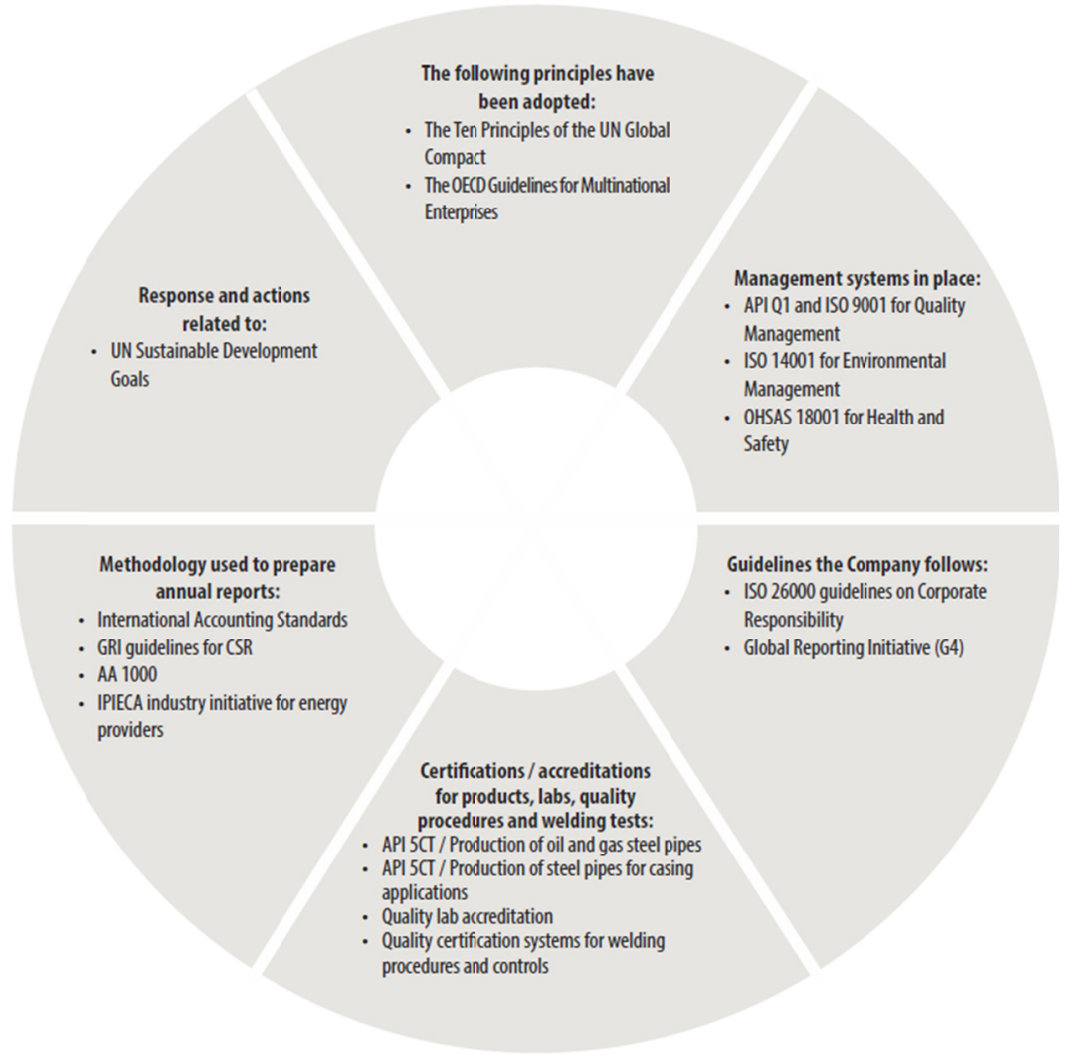

Figure 2. International standards compliance map

\section{a) ISO 26000}

Corinth Pipeworks is in the process of integrating the guidelines of the new ISO 26000 standard into its procedures. As this new model is a framework of guidelines rather than a verifiable management system, the attempt to incorporate its principles is a long and on-going procedure. In particular, the table below presents, per ISO 26000 core subject, the actions and commitments made by the Company: 
ISO 26000 core subjects of social responsibility

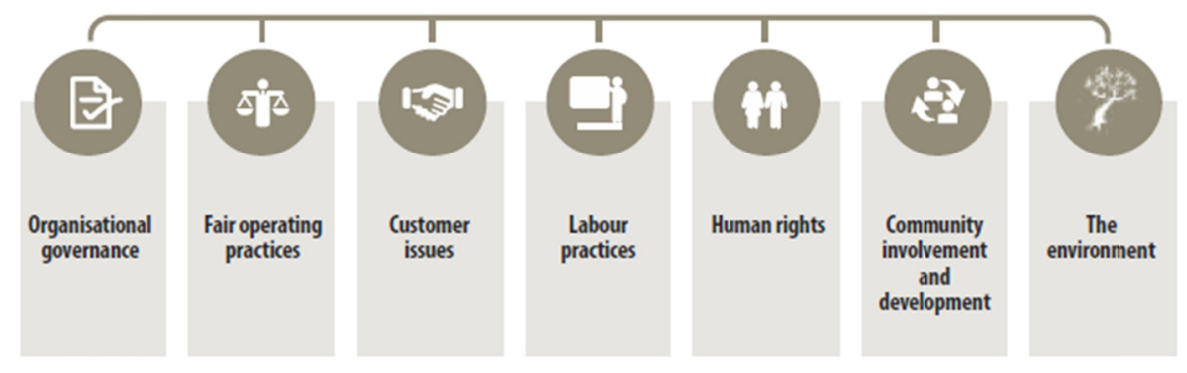

Figure 3. ISO 26000 core subjects of social responsibility

The correlation between the content of Corinth Pipeworks' 2016 Report and the indicators in the GRI-G4 standard and the sections of the new ISO 26000 standard is shown in Table 1 of Appendix.

\section{b) UN Global Compact}

Corinth Pipeworks respects the principles of the UN Global Compact and communicates its actions per Sustainable Development action area through its Annual Report. More specifically, the policies it implements and the actions undertaken by the Company for compliance with the principles of the Global Compact are presented in Table 2 of Appendix. In addition, there is a mapping between the GRI-G4 indicators and the relevant principles of Global Compact.

\section{c) UN Sustainable Development Goals (SDGs)}

Corinth Pipeworks recognizes the importance of developing actions that can, even to a limited extent, contribute to the achievement of the UN Sustainable Development Goals. Based on the international framework of GRI-G4 guidelines that the Company has been implementing for years, it has progressively analyzed the areas of development of actions by goal, as these are linked to the relevant indicators of the Global Reporting Initiative. More specifically, the indicators and fields by goal are indicated in Table 3 of Appendix.

\section{d) Oil and gas industry sustainability reporting guidance}

Corinth Pipeworks prepares its Annual Report according to international standards and initiatives. In the context of broader adoption of these guidelines, the company is in line with the oil and gas industry sustainability reporting guidance. This specific guidance is a result of the collaboration of IPIECA (Global Oil and Gas Industry Association for Environmental and Social Issues), API (American Petroleum Institute) and OGP (International Petroleum and Natural Gas Association).

This industry guidance contains Key Performance Indicators (KPIs), which correspond to relevant indicators of GRI-G4, as presented in Table 4 of Appendix.

\section{e) Greek Sustainability Code}

The compliance with Greek Sustainability Code per company's sustainability pillar and the corresponding criteria are presented in Table 5 of Appendix.

\subsection{Sustainability Pillars}

Sustainability management is of strategic importance to Corinth Pipeworks. It strengthens and maximizes the principles of sustainability by addressing social, economic and environmental issues. Sustainable growth is the only guarantee to secure the future "business" and the production of added value concerns all stakeholders of Corinth Pipework.

Through certified management systems, the Company monitors and evaluates its CSR performance and effectively achieves a comprehensive approach to responsible business issues as well as making Sustainable Development-oriented decisions.

For the better and more effectively management of Corporate Responsibility issues, the Corinth Pipeworks has a Corporate Responsibility team that regularly examines the issues that arise and plans the annual action plan. The Corporate Responsibility Team is composed of representatives of almost all Company Directorates and reports to the General Directorate of Corinth Pipeworks. 
The principles of sustainable development are an integral part of the philosophy governing the business conduct of Corinth Pipeworks. The objective of the Company is through its activities to generate added value for all its stakeholders. The strategic approach of the Company is reflected in the Sustainability Pillars it has defined.

\section{Sustainability pillars}

- Economic growth and Corporate Governance

Achieving positive financial results by adhering to responsible practices.

- Marketplace

Investing in research and development, delivering integrated solutions with high added value.

- Human resources

The Company's employees are its most important asset.

- Occupational health and safety

Safeguarding and ensuring occupational health and safety is a non-negotiable goal for all.

- Environmental protection

Applying the precautionary principle and implementing actions that continually improve the environmental footprint.

- Local communities

Supporting actions that address the key needs of local communities in which the Company operates.

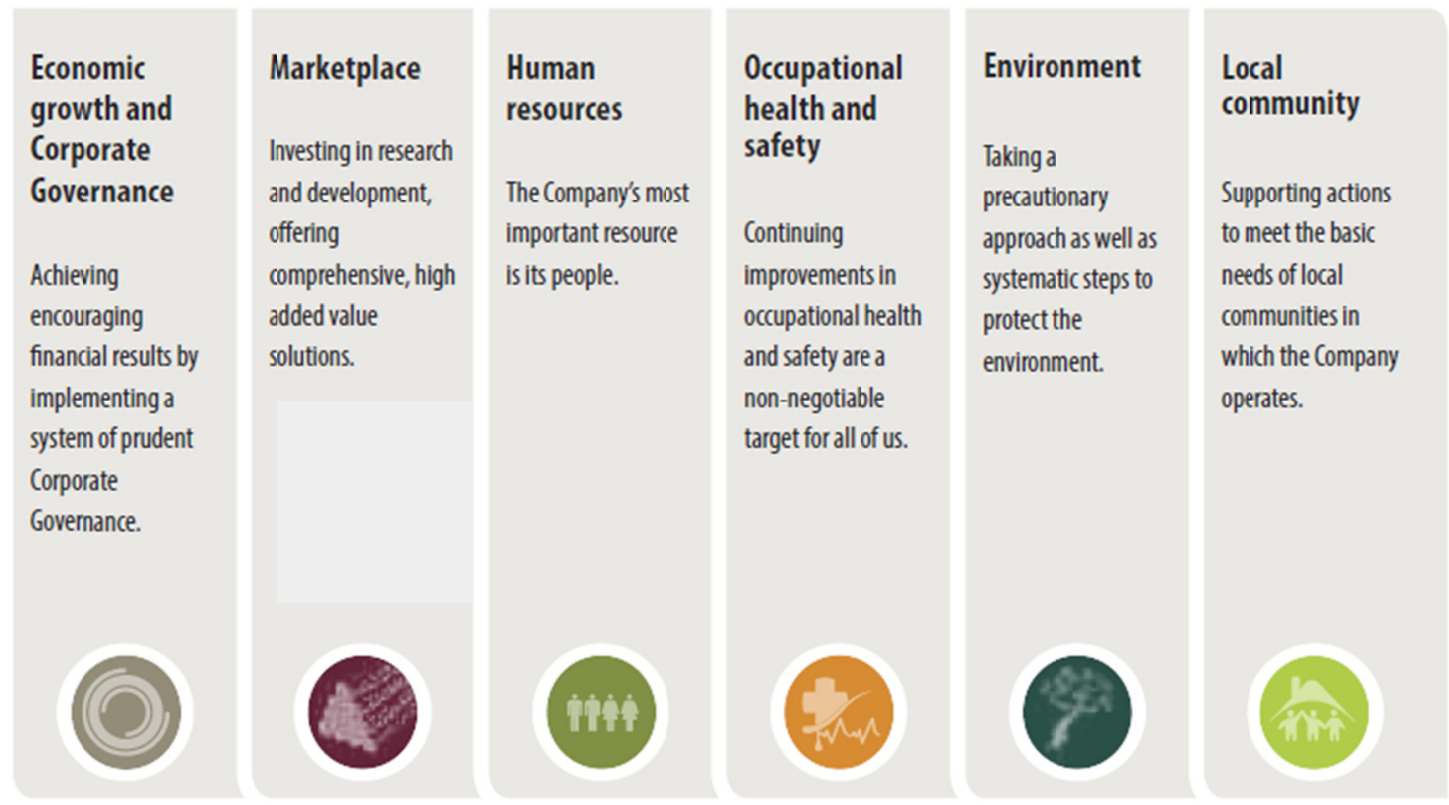

Figure 4. Corinth pipeworks' sustainability pillars

\subsubsection{Economic growth and Corporate Governance}

The Company aims to achieve positive financial results, implement sound corporate governance system, evaluates and manages business risks in order to safeguard the interests of shareholders. It develops procedures and takes measures to enhance transparency, as well as to prevent and combat corruption.

For the implementation of the strategy and the achievement of its objectives, the Company has developed the following integrated organizational structure with two-way communication relations.

\section{a) Board of directors}

The Board of Directors of Corinth Pipeworks is responsible for developing and monitoring the effectiveness of Corporate Governance principles and Corporate Social Responsibility policies. The members of the Board of Directors attach special importance to health, safety and environmental issues, which occupy an important place on the agenda of its meetings. 


\section{b) Audit Committee}

In compliance with the provisions of Law 3693/2008, Corinth Pipeworks has put in place an Audit Committee consisted of three non-executive members of the Board of Directors and aims to support the Board of Directors in its duties on financial reporting, internal control and monitoring of regular audit.

c) Internal audit system

The Internal Audit System aims, among others, to ensure the thoroughness and reliability of the data and information required to accurately and timely determine the Company's financial position and the production of reliable financial statements.

\section{d) Risk management system}

In Corinth Pipeworks, based on the precautionary principle, practices and mechanisms have been developed to identify, categorize, evaluate and manage the risks associated with the Company's business, its exposure to markets and the general economic environment. In this context, the Financial Division implements a specific risk management policy, based on relevant Company guidelines.

e) Avoiding conflicts of interest

In line with the precautionary principle and the protection of the interests of its stakeholders, the Corinth Pipe Works have put in place specific measures and practices to verify, control and address all cases of conflict of interest.

\section{f) Managing transparency and corruption issues}

For Corinth Pipeworks, compliance with ethical and transparency rules in dealing with its stakeholders is one of the key priorities. To achieve its objective, the Company, based on the precautionary principle, establishes the limits of accountability and influence of each of its executives, develops safeguards to prevent corruption, and provides relevant training for transparency and corruption to its executives.

\subsubsection{Marketplace}

The Company aims at optimal and complete customer satisfaction and invests in research and development to provide new products and services of high quality and added value, thus improving its position in the ever evolving business environment. Additionally, responsible business conduct is required from the Company's suppliers and associates.

The Corinth Pipe Workshop has high quality products on the domestic and international markets and offers a range of value-added services that stand out from the competition. The Company's products are distinguished for their technical characteristics, as they are manufactured according to international standards, but also according to the specific requirements and specifications of the customers. More specifically, the Company is able to offer its clients complete solutions, a successful combination of high added value products and specialized services, based on the one-stop-shop philosophy.

In the context of marketplace sustainability pillar the Company addresses and deals with the following key subjects:

- Products and Services

- Facilities - Production process

- Quality management

- Customer service

- Supplier management

- Research and new technologies development

- Major technical projects

\subsubsection{Human Resources}

The Corinth Pipeworks is pursuing a development that goes hand in hand with the prosperity of its people, their families and the wider society in which they operate. Conducting business with the prosperity and growth of its employees, it plans and implements actions and programs to contribute to the relevant Global Objective 8 "Decent Work and Economic Development".

The key issues of the Corinth Pipeworks related to this contribution are: 
- Equal opportunities and equal pay

- Employee training and development

- Employment and recruitment from the local communities

Corinth Pipeworks' people are a key factor in achieving its strategic goals. The Company implements policies and implements programs adapted to the needs of its employees, aiming at maintaining an excellent and safe working environment. In this context, the Company offers continuous training and incentives for further development, enhancing the high level of its employees' expertise.

As a whole, human resources issues and how human resources management are based on three axes, as also presented in the figure 5 below:

- Corporate Culture

- Recognition and rewards

- Empowerment and development

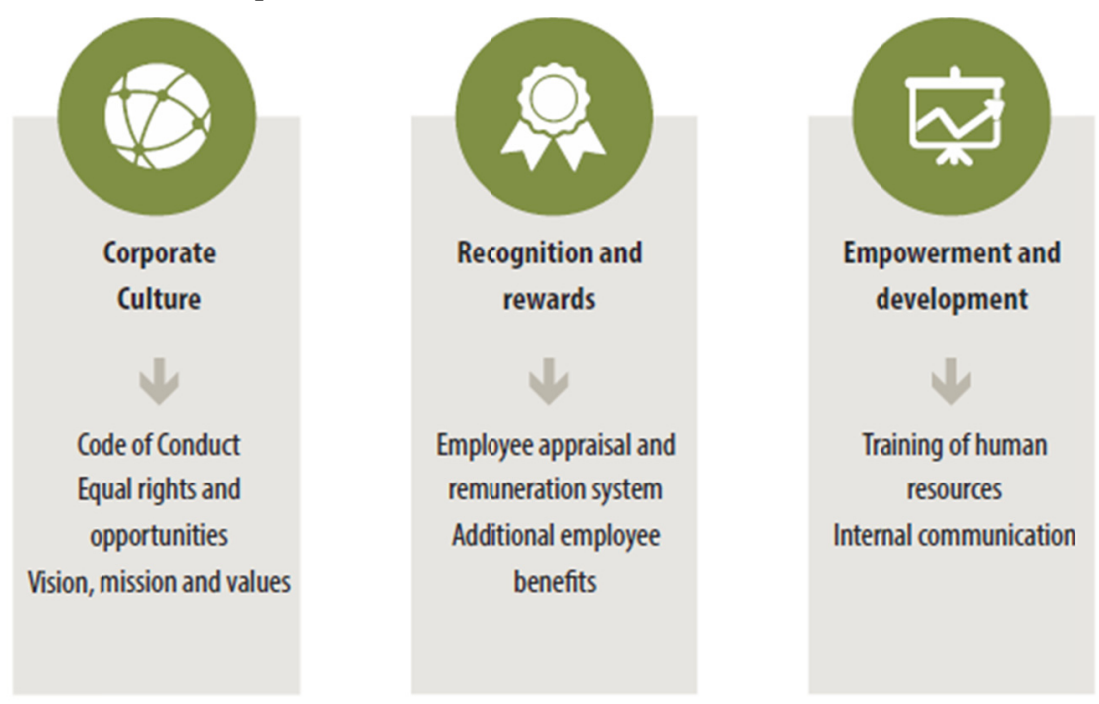

Figure 5. Axes of human resources management

\subsubsection{Occupational Health and Safety}

The protection of the health and safety of employees throughout the entire range of Corinth Pipeworks activities, as well as the elimination of any type of incident or accident in its production facilities, are Company's long-term goals. An Integrated Occupational Health and Safety Management System (OHMS), certified in accordance with the international standard of OHSAS 18001, is in place for the effective management of all relevant issues. The OHMS contributes to the continuous application of measures to minimize occupational risks and accidents and to strengthen the prevention culture.

a) Health and safety management framework

The Company directly and effectively evaluates its performance in health and safety through the implementation of the Health and Safety Management System and the annual review of the Business Risk Assessment Study (BRAS). The company has implemented a series of procedures and processes, as follows, and is committed to continuously improve them with the aim of eliminating accidents and incidents at work.

- Recording and monitoring health and safety issues

- Accident prevention measures

- Employee suggestions

- Incident management procedure

b) Health and safety actions

Corinth Pipeworks cultivates on a daily basis the culture on safety it has adopted and expects all its people to 
adhere to the security rules and behave responsibly in every aspect of their work. Alongside employee awareness programs, the Company implements investments and actions aimed at eliminating risks and ensuring safety in all workplaces, such as:

c) The 5S methodology

Since 2013, Corinth Pipeworks has gradually applied the 5S methodology to its production facilities, as the multiple benefits of its implementation have been recognized. In 2017, the application of holistic 5S has been achieved in all areas of the Company's production facilities, substantially improving working practices.

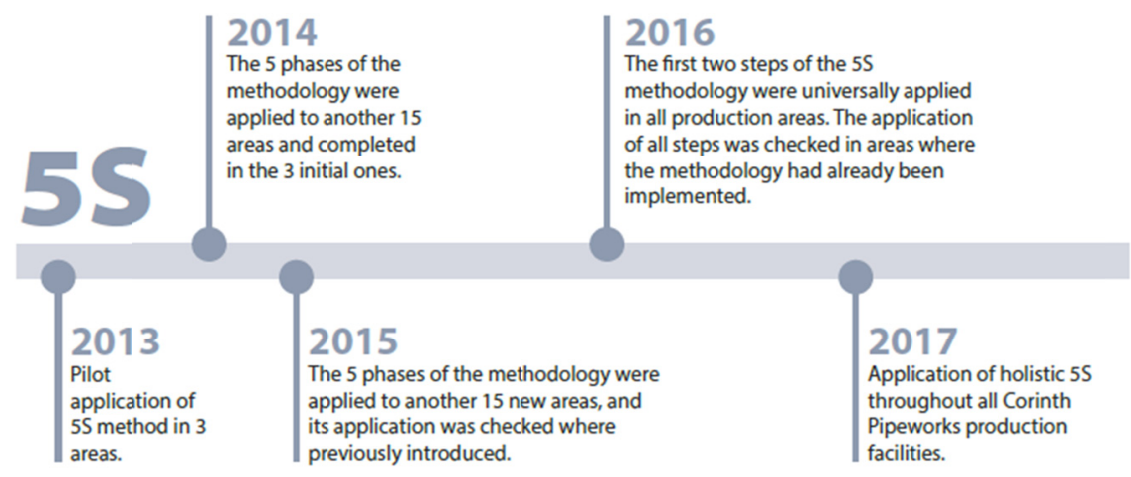

Figure 6. Timeline implementation of 5S methodology

i) Health and safety months

ii) Emphasis on safe working behavior

iii) Emphasis on safe working behavior

\section{d) Health and safety indicators}

The Company records and monitors specific health and safety indicators enabling the timely identification of specific points or areas that require intervention and improvement.

\subsubsection{Environmental Protection}

Focused on operating responsibly, Corinth Pipeworks has recognized as a component of its business development the respect and protection of the environment. The Company strives to reduce its environmental footprint in line with current legislation and international environmental standards and undertakes actions to reduce its emissions by actively contributing to the fight against climate change.

The key priorities issues of Corinth Pipeworks related to environmental protection actions are:

- Integrated environmental management

- Climate change and greenhouse gas emissions

- Waste management

The commitment of the Corinth Pipeworks to continuously improve its environmental performance is based on the adoption of an Environmental Policy and the implementation of an integrated environmental management.

a) Integrated environmental management

Corinth Pipeworks is making every effort to adopt and apply best practices to continuously reduce its environmental footprint. The Company has put an Environmental Management System in place, which is certified according to the requirements of the international ISO 14001 standard.

The Company implements a series of programs aiming at continuous improvement in environmental management and environmental protection.

- Environmental expenditures

- Environmental education and awareness 
Climate change and greenhouse gas emissions

Climate change is a global environmental challenge, the effects of which affect a large number of sectors. Corinth Pipeworks records, controls and takes actions to reduce the emissions released into the atmosphere by its activities, in the following sectors:

- Greenhouse gas emissions

- Thermal energy consumption

- Electricity consumption

- Water consumption

The results of the actions and measures which have been put in place are marking the reduction in each sector during the period of 2015-2017 and is presented in the below figure.
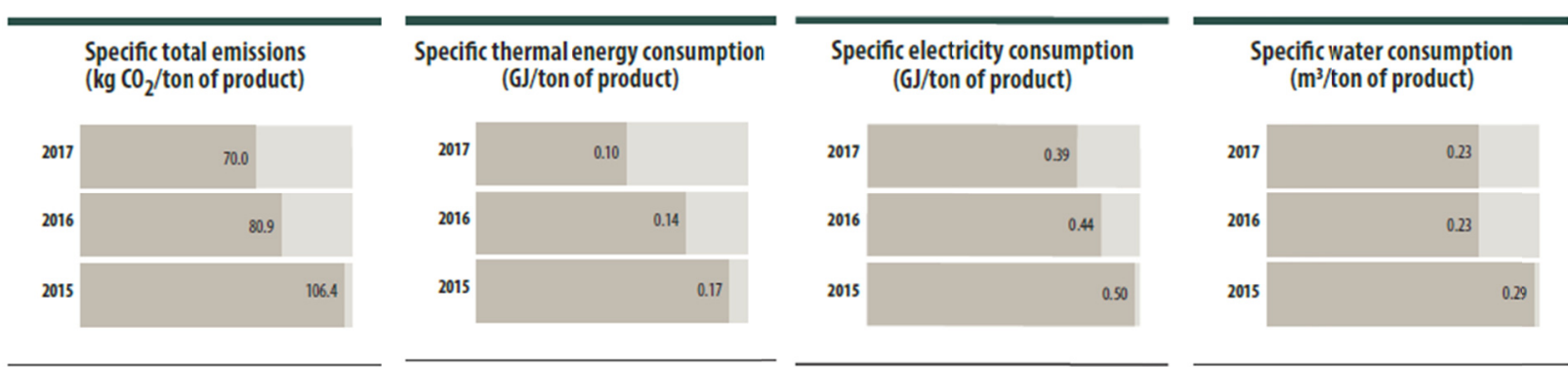

Figure 7. Specific emissions and specific consumption per sector

\section{Waste management}

Corinth Pipeworks implements a specific waste management process, which aims in reducing the volume of waste generated. Most of the waste is recycled, a smaller percentage is earmarked for recovery (energy or other) and the smallest percentage of waste is disposed for landfilling.

\subsubsection{Local Communities}

Corinth Pipeworks by investing time and resources aims to strengthen social cohesion, build cooperative relationships with local communities, and stimulate the social fabric of the country.

The Company ensures the development of harmonious relationships with local communities surrounding it and takes into account the concerns of their residents in decision-making on commonly acceptable actions.

The Company, as an active member of the local communities, records, evaluates and prioritizes the important issues that concern them. Based on the needs that arise, it undertakes actions on the following two key areas:

- Contribution to society

- Supporting local communities

a) Contribution to society

In order to contribute to the development of the local economy, the Company employs staff, by local communities in vast majority, and has developed cooperation with local suppliers.

- Employing staff from local areas

- Supporting local suppliers

b) Supporting local communities

Corinth Pipeworks creates added value ("social contribution") through its business activities. The Company's objective is to contribute to the development of a sustainable social community as well as to the wider economic development of the country, with programs such as:

- Internships at Thisvi plant

- Volunteerism Programme

- Volunteer blood donations

- Community activities 
The Company supports vulnerable social groups, provides sponsorships and donations to local agencies, and supports diverse local community actions, covering an important context of needs. The actions are implemented in the following four (4) main axes:

- Education

- Health and vulnerable social groups

- Culture

- Environment

- Sports

\section{Community actions per action area}

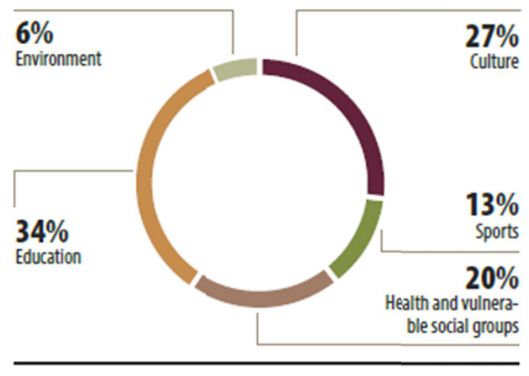

Figure 8. Community actions per axes

\subsection{CSR and Sustainability Performance Assessment}

Corinth Pipeworks has committed to important issues related to its activities and, based on them, it develops a plan of actions and targets on an annual and/or biennial basis.

In this paragraph, the Corinth Pipeworks performance on CSR and aforementioned Sustainability Pillars during the period of interest, namely 2015-2017, will be presented and assessed, according to the targets set each previous year and the generated key performance indicators (KPIs).

In particular, the Company's performance against each previous year's targets, the target setting for each next year and the corresponding key performance indicators of each current year are presented in Table 6 to Table 14 of Appendix.

Specifically, the vast majority of the targets set concerning the period 2015-2017 and the six Sustainability Pillars (Marketplace, Human Recourses, Occupational Health \& Safety, Environment, Corporate Governance and Society) have been achieved.

Moreover, the annual key performance indicators display a positive trend in all areas of interest, such as Economic growth, Employment and Society and a decrease in the figures corresponding to the pillars of Occupational Health and Safety and Environment.

All the above, demonstrate and verify that the Company's business strategy drives Corinth Pipeworks towards the direction of sustainable growth, resulting in a continuous Sustainability Performance improvement.

\section{Conclusion}

From the analysis above, it has become evident that Corporate Social Responsibility is an issue with major prospect the following years. The orientation towards the adoption of a greener profile does not only favors the society, the economy and the environment but also the corporations as entities from the aspect of corporate image and profit and sales augmentation. Corporations can benefit in a tangible and intangible way through the adoption and application of a corporate communication strategy well structured, planed and implied with the correct and well-formed message spread. It is necessary for the companies to establish an accurate and honest inwards and outwards communication in order be at core rather than just seem green. The results of the application of the strategy must always be clear and straightforward without any spot of misleading and deception.

In an attempt to reconcile the achievement of social goals with business opportunity and competitiveness, 
Corporate Social Responsibility, as a voluntary incorporation of social and environmental concerns into corporate practices has established as an international guide largely supported and applauded by corporate executives, NGOs, governments, pressure groups, business academics and international and local development agencies alike. This is manifested in the fact that corporate bodies as well as international development agencies set up CSR-related departments or policies to facilitate its implementation. However, not everybody hails the concept of CSR as some critics question the fundamentals and basis of CSR. Their argument is that businesses should focus on their core objective of profit making and that any deviation from this objective is unjustifiable and inappropriate.

Corporate social responsibility presents itself as a very useful tool for the implementation of sustainable development if the policies are well applied. Defining sustainable development as one which ensures that the developmental needs of present generations are taken care without depriving future generations the ability to provide for their needs, one cannot overlook the importance of the corporate world in ensuring this. It is important for companies and especially mining companies to have the developmental interest of their local communities at heart both during their stay in the company and even after they have abandoned the site. They need to ensure that their activities in the communities affect the local people in the most minimum way possible.

A company that develops corporate social responsibility applications operates on a series of actions that eventually deliver the desired result. These actions, at the first level, concern the respect of the social community, the local society in which the business operates. Then, the health and safety of its human resources, as well as the dialogue between company and employee, is a healthy pursuit of any business that feels strongly responsible of its human part. In addition, the protection of the natural environment, a major issue that is controversial over time, is an end in itself of an enterprise that implements corporate social responsibility practices. The combination of these actions has a significant impact on the market as it presents the image of an enterprise that inspires responsibility, trust and reliability. Thus, it is observed as a whole how the interaction of these actions signifies the prosperity and preservation of a business over time.

For all key issues related to Corinth Pipeworks and its subsidiaries, individual targets for Corporate Social Responsibility and Sustainable Development are set, which are evaluated on an annual basis for their effectiveness and are revised when necessary. The policy, the results of the Corinth Pipeworks on Corporate Social Responsibility, as well as the implementation of the programs and the achievement of the objectives, are published on an annual basis in order to inform all the stakeholders. The views of stakeholders are taken into account in the annual Management Review to all the above issues.

By completing this article, the importance of corporate social responsibility is noted, which emerges as the cornerstone of the success and sustainability of a business. Corporate social responsibility applications are the basis upon which the relationships between a company and society, human resources, the environment and the market are built.

In the present article, an extensive analysis has been applied, in both the theoretical and practical part, and it was examined through the case study how until today the global standards for CSR and SD are applied in the actual enterprise environment. Corinth Pipeworks, as well as the other companies of Viohalco Group, have adopted these practices in their procedures.

Corporate Responsibility is an integral part of the decision-making process of strategy, management, research and development, production and other core sectors of the Corinth Pipeworks. The strategic integration of CSR into the Company also includes the social commitment of Corinth Pipeworks to the local community in which it operates and develops. In addition, developing a stakeholder dialogue helps to better map the impact of its activities on each stakeholder group separately. The systematic dialogue with all stakeholders helps the Company to handle effectively and respond properly to social and environmental issues, as well as to discover new challenges and new areas of activity or opportunities. The strategic integration of CSR in Corinth Pipeworks is realized through planning, engagement with all stakeholders, performance appraisal and continuous improvement.

Having as a basis the information and results the present article has outlined, it could be very important to re-visit and re-examine the same subject, to not only investigate whether the future objectives mentioned in paragraph 4.5, concerning the year 2018 and beyond, have been achieved, but also to examine the evolution of the CSR and SD pillars in global level. Moreover, looking towards the next future steps, a relevant comparative study could be carried out on the Sustainability Reports of not only Corinth Pipeworks, but also of any company in Viohalco Group.

Human, environment and economy, and all their offshoots, are the main pillars for a sustainable future and 
among are the most significant topics of the global agenda. Since the year 2015, relevant targets have been set by the European Union, which is very important to be examined whether they have been achieved in the future.

\section{References}

Athens Chamber of Tradesmen, Moulkiotis, Z. (2009). Corporate Social Responsibility. Retrieved from http://www.ggb.gr/sites/default/files/basic-page-

Commission of the European Communities. (2001). Green Paper: Promoting a European framework for Corporate Social Responsibility. Retrieved from http://ec.europa.eu/transparency/regdoc/rep/1/2001/EN/1-2001-366-EN-1-0.Pdf

Corinth Pipeworks S. A. (2015) Annual Financial and Sustainable Development Report, Athens.

Corinth Pipeworks S. A. (2016) Sustainability Report, Athens.

Corinth Pipeworks S. A. (2017) Sustainability Report, Athens.

CSR Hellas. (2019). Retrieved from https://www.csrhellas.net/network/themata-eke/ti-einai-eke/

Eisenhardt, K. M. (1989). Building Theories from Case Study Research. The Academy of Management Review, 14(4), 532-550. https://doi.org/10.5465/amr.1989.4308385

Elkington, J. (2018) The Elington Report Zen and the Triple Bottom Line. Retrieved from https://www.greenbiz.com/article/zen-and-triple-bottom-line

European Commission. (2001). Promoting a European framework for corporate social responsibility. Green Paper, Luxembourg: Office for Official Publications of the European Communities.

European Commission. (n.d.). Annual Activity Report DG Climate Change Action 2016. Retrieved from https://ec.europa.eu/info/sites/info/files/file_import/aar-clima-2016_en_0.pdf

Ghauri, P. (2004). Designing and conducting case studies in international business research. In R. Marschan-Piekkari, \& C. Welch (Eds.), Handbook of qualitative research methods for international business (pp. 109-124). Cheltenham, UK: Edward Elgar.

Ghauri, P. N. (1983). Negotiating international package deals: Swedish firms in developing countries. Almquist and Wiksell, Stockholm.

Ghauri, P., \& Firth, R. (2009). The formalization of case study research in international business. Journal fur Marketing, 48, 29-40. https://doi.org/10.1007/s12642-009-0003-1

Global Reporting Initiative. (2013). G4 Sustainability Reporting Guidelines, The Netherlands, Amsterdam. Retrieved from https://www.globalreporting.org/resourcelibrary/grig4-part1-reporting-principles-and-standard-disclosures.p df

GRI. (n.d.). Empowering Sustainable Decisions. Retrieve from https://www.globalreporting.org/Pages/default.aspx

International Organization for Standardization, ISO 26000:2010. (n.d.). Guidance on Social Responsibility. Retrieved from https://www.iso.org/obp/ui/\#iso:std:iso:26000:ed-1:v1:en

Slaper, T. F., \& Hall, T. J. (2011). The Triple Bottom Line: What Is It and How Does It Work? Retrieved from http://www.ibrc.indiana.edu/ibr/2011/spring/article2.html

Stake, E. R. (1995). The Art of Case Study Research. London: Sage Publications.

UNDP United Nations. (2012). The future we want, Rio+20 United Nations Conference on Sustainable Development. Rio de Janeiro, Brazil, 20-22 June 2012.

United Nations. (1972). Conference on the Human Environment (Stockholm Conference). Stockholm, Sweden, June 5-16.

United Nations. (1987). Report of the Worls Commission on Environment and Development. 4 August 1987.

United Nations. (1992). Conference on Environment \& Development AGENDA 21. Rio de Janerio, Brazil, 3 to 14 June.

United Nations. (2012). The Future We Want, United Nations Conference on Sustainable Development. Rio de Janeiro, Brazil, 20-22 June 2012 Retrieved from https://sustainabledevelopment.un.org/content/documents/733FutureWeWant.pdf 
United Nations. (2015). Paris Agreement. Retrieved from https://unfccc.int/sites/default/files/english_paris_agreement.pdf

United Nations. (2018). Kyoto Protocol to the United Nations Framework Convention on Climate Change. Retrieved from https://unfccc.int/resource/docs/convkp/kpeng.pdf

United Nations. (n.d.). Transforming our World: The Agenda 2030 for Sustainable Development. Retrieved from https://sustainabledevelopment.un.org/content/documents/21252030\%20Agenda\%20for\%20Sustainable $\% 2$ 0Development $\% 20$ web.pdf

United Nations. (n.d.). UNFCCC Financial Statements 2016. Retrieved from https://unfccc.int/sites/default/files/2016fs.pdf

Woodside, A., \& Wilson, E. (2003). Case study research methods for theory building. Journal of Business \& Industrial Marketing, 18(6/7), 493-508. https://doi.org/10.1108/08858620310492374

Word Commission for the Environment and Development-WCED. Retrieved from https://sustainabledevelopment.un.org/milestones/wced

World Bank. (1998). Corporate Environmental Responsibility: Is a common CSR framework possible? Retrieve from https://siteresources.worldbank.org/EXTDEVCOMSUSDEVT/Resources/csrframework.pdf

World Summit on Sustainable Development, 26 August - 4 September 2002, Johannesburg, South Africa. Retrieved from http://enb.iisd.org/2002/wssd/WSSDcompilation.pdf

Yin, R. (2009). Case study research, Design and methods. London: SAGE Inc.

Yin, R. K. (2003). Case study research: Design and methods (3rd ed.). Thousand Oaks, CA: Sage.

\section{Copyrights}

Copyright for this article is retained by the author(s), with first publication rights granted to the journal.

This is an open-access article distributed under the terms and conditions of the Creative Commons Attribution license (http://creativecommons.org/licenses/by/4.0/). 